\title{
Trayectorias de la sistematización de experiencias. Su constitución como posibilidad de pensar la producción de conocimiento en escenarios académicos ${ }^{1}$
}

Carlos Cogollo ${ }^{2}$

Recibido: 03-03-2016

Aceptado: 23-05-2016

\section{RESUMEN}

El presente artículo muestra, mediante una exploración documental, las trayectorias que han permitido a la sistematización de experiencias pasar de ser en sus orígenes una propuesta política de organización comunitaria de la América Latina de los años sesentas, a constituirse en una apuesta por la producción de conocimiento en escenarios académicos. El documento es construido retomando a los autores más representativos sobre el tema de sistematización de experiencias. Así mismo, busca mediante el rastreo realizado evidenciar algunas categorías en función de los soportes epistemológicos y los enfoques metodológicos, que fundamentan la sistematización, finalmente se intenta, a partir del recorrido propuesto, dar respuesta a la pregunta ¿Qué hacemos cuando sistematizamos?

Palabras clave: Sistematización de experiencias, metodologías de investigación, producción de conocimiento.

1. Artículo producto de la investigación Tensiones y aprendizajes de la Sistematización de experiencias: la investigación como marco de formación educativa y política. Maestría en Educación. Vicerrectoría de la Universidad Abierta y a Distancia VUAD Santo Tomás.

2. Historiador. Magíster en Estudios Sociales. Especialista en Métodos de Investigación Social. Docente de la Universidad Abierta y a Distancia VUAD Santo Tomás y de la Universidad Pedagógica Nacional. Bogotá, Colombia.

Correo: carloscogollo@ustadistancia.edu.co 


\title{
Trajectories of the systematization of experiences. Its constitution as a possibility of thinking about knowledge production in academic settings
}

\begin{abstract}
This article presents by documentary exploration retaking the most representative authors, the paths that have enabled the systematization of experiences go from being originally a political betting community organization of the Latin America of the sixties to become a bet for the production of knowledge in academic settings. Also, by tracking searches performed some authors, find its founding categories based on the epistemological and methodological approaches media, trying to round off to answer the question: What do we do when we systematized?
\end{abstract}

Key words: Systematization of experiences, research methodologies, knowledge production.

\section{Introducción}

La intención de este artículo es evidenciar los trayectos de la sistematización de experiencias en su consolidación como apuesta epistémica, metodológica, ética y política para la producción de conocimiento en escenarios académicos. Su reciente incorporación en escenarios de orden académico, evidencia una vieja tensión entre las formas técnico-científicas instaladas para la producción de conocimientos en lo que a la universidad colombiana se refiere. Es interesante repasar que fuerzas han hecho posible ese tránsito, que va desde la organización comunitaria, hasta la posibilidad de pensarse como una forma valida y ya validada de investigación. La ruta propuesta explora el origen en lo que hemos llamado el escenario político - la educación popular y los escenarios académicos, para dirigirse a presentar la ruptura que supone la sistematización de experiencias con las formas "tradicionales" de producción de conocimiento, para finalizar intentando dar respuesta a la pregunta ¿Qué hacemos cuando sistematizamos? Todo construido desde una exploración documental que retoma a los autores más representativos de la sistematización de experiencias. 


\section{Orígenes. El escenario político}

Ubicar el origen de la sistematización de experiencias, refiere a pensar a Latinoamérica como contexto de emergencia. Algunos autores indican que la Revolución cubana como idea de transformación y posibilidad de constituir discursos y prácticas políticas contextualizadas, tuvo un importante impacto en el desarrollo de esta práctica investigativa.

Su aporte de orden político (el de la revolución), se manifestó en la intención de concretar por parte de los Estados de la región y del gobierno estadounidense y como forma de contención a una posible oleada de procesos revolucionarios, la implementación del modelo de desarrollo y modernización con la promesa de la trasformación estructural en términos productivos, económicos y de mejora de la calidad de vida de los habitantes de toda América Latina, en la llamada "Alianza para el Progreso": "por ello, temas como el del 'Desarrollo' y de la 'Modernización' se pusieron de moda. Ellos venían acompañados de modelos de intervención social y comunitaria dirigidos a incorporar a la población en estos proyectos pensados y dirigidos desde afuera" (Jara, 2002, p.4).

La puesta en marcha de la maquina desarrollista comienza por amplios y profundos procesos de escolarización y alfabetización, debido en parte a que se había establecido una relación directa entre educación y desarrollo. Desde este enfoque, se promueven los programas de educación de adultos, sobre todo en el sector agrícola con el fin de industrializar el campo y optimizar su capacidad productiva. Entre otros escenarios la promoción de las organizaciones comunitarias, las asociaciones de vecinos y campesinos, con miras a impulsar procesos formativos en el marco de la educación de adultos, son los que proporcionan un conjunto de condiciones a los colectivos y organizaciones para cuestionarse acerca de las experiencias adelantadas, los modelos implementados y sobre todo sus nulos avances en términos de alcanzar la promesa del desarrollo

Dichos modelos de intervención pronto pasaron a sercuestionados y confrontados desde una perspectiva de transformación social, generándose a partir de allí una serie de procesos de crítica, replanteamiento y redefinición tanto de los paradigmas de interpretación como de los métodos de acción social. El nuevo contexto histórico-social de nuestra América promueve, entonces, el surgimiento de un nuevo "contexto teórico" en el que 


\section{De la educación de adultos a la educación popular}

De forma casi paralela, hacia los años 60 en Brasil se gestaba de la mano del maestro Paulo Freire, un gran salto de orden cualitativo en el sentido de la politización de los procesos organizativos vinculados a la educación de adultos. A partir de su concepto de "concientización", Freire (2004) establece una nueva idea de la relación: ser humano-sociedad-cultura, proponiendo una nueva concepción de los actos educativos adelantados en los Centros Populares de Cultura y los movimientos de educación de base, recogiendo su propuesta en lo que se llamó "educación Popular" con un sentido profundamente político y transformador y en clara oposición a lo que llamó educación bancaria y reproductora del statu quo.

Los aportes de Freire, son acogidos por las organizaciones populares de la región, constituyéndose estos escenarios en la base para el desarrollo de las primeras apuestas por recoger los procesos adelantados, evaluar los avances y retrocesos y constituir el proceso mismo y a los sujetos que los adelantaban en sujetos de saber y procesos de aprendizaje para el campo de saber de lo comunitario y colectivo

Estas tensiones reflejan una preocupación de orden político, teórico, metodológico y operativo que llevan a destacar una necesidad cada vez más sentida, de ir redefiniendo el quehacer, ganando mayor claridad en las propuestas. Esto implicaba proponerse recuperar y reflexionar críticamente la práctica para posibilitar un salto cualitativo que las circunstancias y las transiciones socio políticas, económicas y culturales demandaban. (Jara, 2002, p.3)

\section{Escenario académico}

Los cuestionamientos a los procesos adelantados por los mismos sujetos de las organizaciones sociales, son identificados y organizados por los profesionales que los acompañaban, en este caso, es desde el trabajo 
social que se promueven los primeros procesos de sistematización

Leticia Cáceres y María Rosario Ayllón ubican los antecedentes de la sistematización en el campo del Trabajo Social entre los años 50 y 60 , relacionados con la profesionalización del Servicio Social bajo influencia norteamericana, la cual pregonaba el "metodologismo ascéptico". Así, el sentido inicial con el que se usaba el término sistematización, se centraría en: "recuperar, ordenar, precisar y clasificar el saber del Servicio Social para darle un carácter científico-técnico a la profesión y elevar su status ante otras especialidades". (Jara, 2002, p. 4).

Desde esta primera entrada a la sistematización de prácticas, el campo disciplinar pasa a preguntarse por la misión social y transformadora de su labor, movilizándose hacia una nueva idea la sistematización, así. "se atribuye a la Sistematización la misión de recuperar y reflexionar sobre las experiencias como fuente de conocimiento de lo social para la transformación de la realidad, objetivo inherente a la naturaleza del trabajo social tal como era definido en ese período". (Jara, 2002, p. 5).

De acuerdo con Jara (2002), la gran transformación en este proceso - en términos de la intervención disciplinar - radica en la idea subyacente según la nueva perspectiva dada a la disciplina del trabajo social, en cuanto asume que los problemas y formas de intervención de las situaciones sociales latinoamericanas, se constituyen de forma situada y que en las comunidades de la región, se observan formas organizativas, demandas, soluciones y rutas con un carácter particular, lo que singularizaba sus situaciones y por tanto sus formas de intervención. Nace así la idea de que en las prácticas adelantadas subyacía un saber que debía ser recuperado, organizado, evaluado, interpretado y sobre todo comunicado. Emerge en este escenario un nuevo "sujeto epistémico", gestado en la práctica y lo colectivo.

\section{Distanciamiento del método científico. Hermenéutica vs positivismo}

Las bases establecidas en el marco de la educación popular, permiten la emergencia de una nueva práctica investigativa que tiene como objeto de su indagación la experiencia construida en torno a prácticas de origen 
comunitario. En términos políticos, estas prácticas investigativas buscan la transformación social. En términos epistémicos el saber se ubica en los sujetos de la práctica y en ese sentido, la subjetividad se constituye en un elemento sustancial de la ecuación. Hacia la década de 1970, para la comunidad científica latinoamericana el positivismo se erigía como la única ruta posible para la producción de conocimiento, su sentido en la investigación social altamente explicativo y su mayor constructo sobre la "verdad": separación sujeto - objeto, operaban con rigor en las investigaciones que los cuerpos académicos producían en torno a lo social: "El ideal positivista fue establecer una distancia entre investigador y objeto investigado, correlacionando mayor despersonalización con incremento de objetividad. La investigación narrativa viene justo a negar dicho supuesto, pues los informantes hablan de ellos mismos, sin silenciar su subjetividad". (Bolívar, 2002, p. 2)

Como parte de las prácticas emergentes de producción de conocimiento para la época, la sistematización de experiencias tienen como distintivo la apuesta por la producción de conocimiento en dimensiones como la subjetividad, entendida esta en el ámbito de la construcción colectiva; la experiencia, situada en la construcción de lo subjetivo (ámbito de la construcción individual, en relación directa con lo colectivo); las prácticas, como escenarios para la recuperación de saberes y la construcción de conocimientos $y_{i}$ el horizonte ético - político como "posibilidad" para la trasformación social. De esta manera, se evidencia el "giro epistémico" en tanto práctica investigativa al margen de la producción de conocimiento mediante el método científico de carácter positivista.

Así, la hermenéutica se constituye en el soporte epistemológico de la sistematización de experiencias como práctica investigativa academizada: "Dilthey, a comienzos del siglo pasado, contribuyó decisivamente a dar un estatuto epistemológico propio a las ciencias humanas (Geisteswissenschaften), situando las relaciones personales vividas por cada individuo como clave de la interpretación hermenéutica. Dichas experiencias vividas (erlebnis, que Ortega y Gasset tradujo por 'vivencias') son la base de la comprensión (verstehen) de las acciones humanas". (Bolívar, 2002:2), y son las acciones humanas, situadas en el "mundo de la vida", las que constituyen el sustrato de la construcción de conocimiento en la sistematización de experiencias. De acuerdo con Bolívar (2002),

Desde la fenomenología, Husserl (1991), en los años treinta, realizó (La crisis de las ciencias europeas y la fenomenología transcendental) 
un lúcido análisis de cómo la ciencia moderna (Galileo-Descartes) excluyó el "mundo de la vida" (lebenswelt), por lo que se "hace abstracción de los sujetos en cuanto personas con una vida personal". Muchos de los problemas que arrastramos para encajar la investigación narrativa en la investigación tradicional provienen de esta separación que introdujo la ciencia moderna. Dicha exclusión argumenta- no estaría justificada en cuanto que el mundo objetivocientífico se fundamenta en el lebenswelt (mundo de la vida), base previa y originaria de toda evidencia. Para ello propone, en lugar de reducirlo a la objetividad científica, "tomar el mundo puramente y de forma totalmente exclusiva tal y como el mundo tiene sentido y validez de ser en nuestra vida de consciencia [...], como subjetividad productora de validez". (р. 3)

En este orden de ideas, Ghiso (1998) propone unos soportes epistemológicos que tienen como matriz común el enfoque hermenéutico:

Tabla 1. Soportes Epistemológicos desde el Enfoque Hermenéutico. Según Ghiso 1998.

\begin{tabular}{|c|c|}
\hline Enfoque & Descripción \\
\hline $\begin{array}{l}\text { Enfoque histórico - } \\
\text { dialéctico }\end{array}$ & $\begin{array}{l}\text { En el que las experiencias hacen parte de una práctica social e } \\
\text { histórica general e igualmente dinámica, compleja y contradictoria } \\
\text { que pueden ser leídas y comprendidas, de manera dialéctica } \\
\text { entendiéndolas como una unidad rica y contradictoria, plena de } \\
\text { elementos constitutivos que se hallan en movimiento propio y } \\
\text { constante. Estas prácticas están en relación con otras similares en } \\
\text { contextos que permite explicarlas. (Ghiso,1998, p. 7) }\end{array}$ \\
\hline Enfoque hermenéutico & $\begin{array}{c}\text { Aquí se pone en consideración la necesidad de entender a los } \\
\text { actores de los proyectos socioculturales y educativos en el desarrollo } \\
\text { de razones prácticas reflexivas, mediante una serie de procesos } \\
\text { que permiten hacer explícitos y ponen en claro: intencionalidades, } \\
\text { predisposiciones, hipótesis, sentidos y valoraciones que subyacen } \\
\text { en la acción. Es desde este enfoque, que la sistematización se } \\
\text { entiende como una labor interpretativa de todos los que participaron, } \\
\text { develando los juegos de sentido y las dinámicas que permiten } \\
\text { reconstruir las relaciones que se dan entre los actores, los saberes y } \\
\text { los procesos de legitimidad, esto es dar cuenta de la densidad cultural } \\
\text { de la experiencia. Desde este enfoque se afirma: "sistematizamos } \\
\text { experiencias, esto es interpretaciones de un acontecimiento, desde el } \\
\text { espesor sociocultural de cada uno de los participantes". (Ghiso, 1998, } \\
\text { p.7) }\end{array}$ \\
\hline
\end{tabular}




\begin{tabular}{|c|c|c|c|}
\hline $\begin{array}{c}\text { Enfoque de la reflexividad } \\
\text { y la construcción de la } \\
\text { experiencia humana }\end{array}$ & $\begin{array}{c}\text { Estos enfoques asumen la implícita epistemología de la práctica, } \\
\text { basada en la observación y el análisis de los problemas que no tienen } \\
\text { cabida en el cuerpo teórico aprendido o aplicado. La sistematización } \\
\text { está vinculada aquí a la resolución de problemas permitiendo } \\
\text { hacer frente a los nuevos desafíos que les presenta el contexto. La } \\
\text { sistematización busca entonces recuperar el saber tácito, que está } \\
\text { implícito en las pautas de acción, en la percepción del problema que } \\
\text { se afrontó. Se reconoce y valora el saber, los juicios y destrezas } \\
\text { que están invisibilizadas en la acción. En este tipo de procesos se } \\
\text { descubre que, al recuperar y reflexionar la experiencia, el sujeto } \\
\text { se reconoce observando, hablando y actuando y esto le permite el } \\
\text { deslinde de la experiencia de su lógica de explicación, en el mismo } \\
\text { acto de comprenderla y explicarla. (Ghiso, 1998, p. 9) }\end{array}$ \\
\hline $\begin{array}{c}\text { Desde este enfoque podría entenderse la sistematización como } \\
\text { una intervención que permite entrar en la voz, en la autoconciencia } \\
\text { de lo institucional, en los imaginarios y en aquellos campos donde } \\
\text { existen formas institucionalizadas de ejercicio del poder. Es un oír las } \\
\text { márgenes de la maquinaria institucional, sospechando de todo aquello } \\
\text { que se afirma que está funcionando bien. Se construye conocimiento } \\
\text { al reconocer las huellas que dejan la acción y los orígenes de la } \\
\text { misma, ya que éstos nunca desaparecen. Desde esta perspectiva la } \\
\text { condición epistemológica es la de la incertidumbre que propicia a lo } \\
\text { largo del proceso de sistematización la generación de preguntas que } \\
\text { colocan a los actores en la posibilidad de abandonar lo que se es, } \\
\text { para colocarse en un horizonte de construcción de lo que puede ser. } \\
\text { (Ghiso, 1998, p.9) }\end{array}$ \\
\hline
\end{tabular}

Fuente. Reconstrucción propia a partir de Ghiso (1998).

Como parte dela investigación cualitativa, suscrita en la idea de comprender y transformar, la sistematización de experiencias completa sus cimientos epistémicos en la propuesta de Orlando Fals Borda, quien plantea para América Latina la Investigación Acción Participativa: "entendida como un enfoque investigativo que busca la plena participación de las personas de los sectores populares en el análisis de su propia realidad, con el objeto de promover la transformación social a favor de éstas personas: oprimidas, marginadas y explotadas" (Jara, 2002, p. 9).

El diálogo horizontal entre sujetos y la construcción de conocimiento de sus fundamentos epistemológicos, con su correlato en las prácticas investigativas, constituye un componente esencial en la sistematización de experiencias, renunciando enfáticamente a la dicotomía que supone la relación sujeto-objeto, es decir, la objetivación del sujeto mismo como referente investigativo, lo cual nos indica que desde la mirada investigativa de la sistematización de experiencias, el saber que se origine es el resultado del encuentro, de la intersubjetividad, la cual "corresponde al diálogo entre sujetos y saberes, a la intercomunicación como característica primordial de un contexto, que como parte del mundo, es ante todo cultural e 
histórico, en tanto es construido y significado colectiva y socialmente". (Freire, 1977, p. 4)

Los fundamentos críticos - transformativos de la sistematización evidencian un estatuto epistémico que da cuenta de los posicionamientos éticos y políticos de quien sistematiza, en tanto sus búsquedas proponen rutas de margen y líneas de fuga:

Se reconoce un estatus crítico que avanza hacia nuevas configuraciones de la pedagogía que afectan en forma profunda la relación de aprendizaje. Se apoya en una metodología orientada intencionalmente a dotar de sentido las experiencias de los sujetos, de cara a procesos de transformación social, con lo cual se supera la idea instrumental de una sistematización que simplemente ordena lo que está disperso. Se reconoce la importancia de enfocar los procesos que conducen a las transformaciones y no solamente resultados que desdibujan las circunstancias que devienen en alternativas y cambios. Se introduce la subjetividad en su planteamiento metodológico, en tanto que se orienta a reconstruir críticamente la historia desde la perspectiva de los actores, desde sus memorias mediadas por los afectos, los sentimientos, las pulsiones y no desde la razón o desde categorías teóricas previamente establecidas. (Piedrahita, 2011, p. 16)

El anterior posicionamiento, se constituye en un argumento sumamente potente en la construcción de formas educativas e investigativas conducentes a procesos de afirmación de "otros" conocimientos, problemas, epistemologías, estéticas, expresiones políticas y politización real de situaciones y sujetos. Desde su posicionamiento ético - político, y en su apuesta metodológica, sistematizar supone, además de recuperar saberes, visibilizar la voz del otro: educando - co-investigador en sus propios códigos, que transmitan sus significados y a la vez, le sean significativos en sus formas de decir-se y de decir su propio mundo en relación con cualesquier otro.

Como colofón, podemos afirmar que desde sus orígenes, la sistematización de experiencias ha impactado profundamente las prácticas investigativas, proponiendo en tono de resistencia que los sujetos, los contextos, los problemas, las tensiones, las preguntas, las metodologías, las prácticas, las experiencias, los saberes y las concepciones acerca del conocimiento no se pueden universalizar, que los resultados de la investigación son situados y útiles, en tanto sus objetivos propicien transformaciones para los sujetos del proceso. 


\section{A manera de cierre. Posicionamientos entorno a ¿qué hacemos cuando sistematizamos?}

En su propia historicidad la sistematización ha transitado desde una concepción de organizar, clasificar y ordenar, a entenderse como práctica investigativa que recupera saberes subyacentes en las experiencias adelantadas por sujetos, en la que sus voces, sentimientos, sentidos y apuestas, proporcionan rutas y posibilidades de agencia y autogestión en el orden social, organizativo, educativo y epistemológico. En la actualidad podemos identificar al menos tres posicionamientos en torno a ¿qué hacemos cuando sistematizamos? Cada una de estas posturas ha configurado elementos identitarios en función de su enfoque epistemológico, ruta metodológica, técnicas e instrumentos aplicados, preguntas, ejes de sistematización y sujetos epistémicos, entre otros. Sin embargo, y pese a que estas posturas fungen en la práctica de forma sistémica e independiente, existen una suerte de matriz fundante que las tres comparten.

Dicha matriz estaría sustentada en un "respaldo epistemológico común, que denomino como: oposición al positivismo que guía el quehacer de las ciencias sociales desde una 'epistemología dialéctica': dialéctica de la historia en su tensión primordial marcada por sujetos en conflicto y los cambios por ellos generados en sus realidades y dialéctica epistémica marcada por los ciclos: practica - teoría - práctica" (Ghiso, 1998, p. 7)

En este sentido, se establecen a su vez acuerdos en torno a: toda sistematización debe ser producto de una práctica; todos los sujetos inmersos en la experiencia son sujetos de saber; la sistematización es un proceso dialógico e intersubjetivo; por su carácter subjetivo una sistematización no es un proceso neutro; por su carácter formativo en la sistematización el producto y el proceso son igualmente relevantes. En términos de los elementos diferenciadores, según Diego Palma (citado en Ghiso, 1998), existen tres aspectos básicos diferenciadores en los enfoques: objetivos específicos, objeto a sistematizar y metodologías.

Desde otra perspectiva, la sistematización se entiende a partir de dos vías que expresan sus sentidos y objetivos. Por un lado, la sistematización que se hace desde la academia o desde la investigación sobre sistematización y por otro, la sistematización que hacen los agentes sociales o los sujetos que están inmersos en las experiencias. 
De forma general "asumimos que la sistematización como concepto y práctica metodológica no tiene un significado único. Por el contrario, gran parte de su riqueza radica en la diversidad de enfoques que se utilizan y que dan cuenta de la contextualización y sentido práctico que se otorga a la reflexión de la experiencia" (Martinic, 1998, p. 2)

De acuerdo a Torres y Cendales (2006) "Toda sistematización, como modalidad colectiva de producción de sentidos, es siempre una experiencia inédita, dado que lo que se ponen en juego no son un conjunto de procedimientos y técnicas estandarizadas, sino las vivencias, sueños, visiones y opciones de individuos y grupos que la asumen como posibilidad de auto comprensión y transformación" (Torres y Cendales, 2006, p. 1).

Como acuerdo inicial, se puede establecer que sistematizar experiencias remite a un conjunto de posturas, objetivos, intereses, posicionamientos, intenciones y necesidades en contextos específicos, en experiencias inéditas e irrepetibles, situadas histórica y socialmente. En ese sentido, cuando sistematizamos podemos dirigirnos entre otros, hacia los siguientes propósitos:
* Producir un balance de lo construido en la experiencia.
* Recuperar la experiencia, ahora a modo de saberes producidos.
* Reflexionar en torno a las trayectorias y los aprendizajes individuales o colectivos generados en la experiencia.
* Promover una visión crítica de la trayectoria e incidencias de la experiencia.
* Propiciar una modalidad participativa de producción de conocimiento.
* Como proceso formativo.

Estos propósitos, se encuentran integrados en lo que podríamos denominar los "Enfoques en la sistematización de experiencias". Estos enfoques se identificarían, especialmente, en función de los objetivos que se establecen en cada proceso de sistematización así, proponemos la siguiente clasificación:

* La sistematización de experiencias, como ejercicio de producción de conocimiento crítico desde la práctica, en la vía de lo propuesto por Oscar Jara, Alfredo Ghiso, Alfonso Torres y Mercedes Barnechea. 


\section{* La sistematización como escenario de formación en y desde la práctica, desde la perspectiva de Alfonso Torres, Lola Cendales, Oscar Jara y Alfredo Ghiso. \\ * La sistematización como práctica investigativa. Alfonso Torres, Alfredo Ghiso y Oscar Jara.}

En los ejercicios de sistematización esta clasificación, acaso inexacta, opera solo en el sentido de lo antes mencionado, en su relación directa con la intencionalidad con que se emprende el proceso sistematizador. No obstante a cada propósito subyace un posicionamiento de orden político - ético y epistémico y tránsitos en términos de la ruta metodológica y las técnicas e instrumentos utilizados.

Tabla 2. Tipificación: enfoques en la Sistematización de Experiencias

\begin{tabular}{|c|c|}
\hline $\begin{array}{l}\text { Enfoques en la } \\
\text { sistematización }\end{array}$ & Características \\
\hline $\begin{array}{l}\text { La sistematización de } \\
\text { experiencias, como } \\
\text { ejercicio de producción de } \\
\text { conocimiento crítico desde } \\
\text { la práctica }\end{array}$ & $\begin{array}{l}\text { "Procedimiento heurístico que, apelando a la reflexión de la experiencia } \\
\text { como fuente de conocimientos sobre prácticas contextuadas". (Ghiso, } \\
1998, \text { p. 5) } \\
\text { "Modalidad de producción de conocimiento: las reflexiones provenientes } \\
\text { no de teorías o parámetros predefinidos, sino surgidas del encuentro y } \\
\text { mirada crítica a las experiencias vivas, reales y en construcción" (Ghiso, } \\
1998, \text { p. 8) } \\
\text { "Se trata de un proceso que tiene el propósito de generar nuevos } \\
\text { conocimientos o enriquecer los existentes a partir de una experiencia de } \\
\text { intervención intencionada"(Jara, 2012, p. 10) } \\
\text { "Permite obtener un producto consistente y sustentado, a partir del } \\
\text { cual es posible transmitir la experiencia, confrontarla con otras y con el } \\
\text { conocimiento teórico existente, y así contribuir a una acumulación de } \\
\text { conocimientos generados desde y para la práctica". (Barnechea, 1994, } \\
\text { p. 13) } \\
\text { "Proceso permanente y acumulativo de creación de conocimientos a } \\
\text { partir de nuestra experiencia de intervención en una realidad social". } \\
\text { (Barnechea, 1994, p. 2) } \\
\text { "En la medida que las prácticas, ubicándose en el espacio de lo cotidiano, } \\
\text { forman parte de un contexto mayor, el conocimiento producido en ellas } \\
\text { debe entrar en diálogo y aportar hacia lo general" (Barnechea, 1994, p. 10) }\end{array}$ \\
\hline $\begin{array}{l}\text { La sistematización como } \\
\text { escenario de formación en y } \\
\text { desde la práctica }\end{array}$ & $\begin{array}{l}\text { "En la sistematización interesa tanto el proceso como el producto. El } \\
\text { proceso vincula múltiples componentes uno de ellos es el pedagógico; } \\
\text { nos formamos para sistematizar y sistematizando nos formamos. Estamos } \\
\text { hablando aquí de aprendizajes altamente significativos para los que } \\
\text { participan" (Ghiso, 1998, p. 6) } \\
\text { "En la sistematización la formación es una condición y rasgo definitorio } \\
\text { porque es la garantía de la participación, de la apropiación de la } \\
\text { metodología y de la calidad de la comprensión de la experiencia" (Torres } \\
\text { y Cendales, 2006, p. 9) } \\
\text { "La experiencia misma de sistematizar es formativa porque incorpora o } \\
\text { reactiva prácticas y habilidades investigativas como la lectura, la escritura, } \\
\text { el análisis de información y la conceptualización, en muchos casos } \\
\text { marginal a las experiencias populares" (Torres y Cendales, 2006, p. 10) }\end{array}$ \\
\hline
\end{tabular}




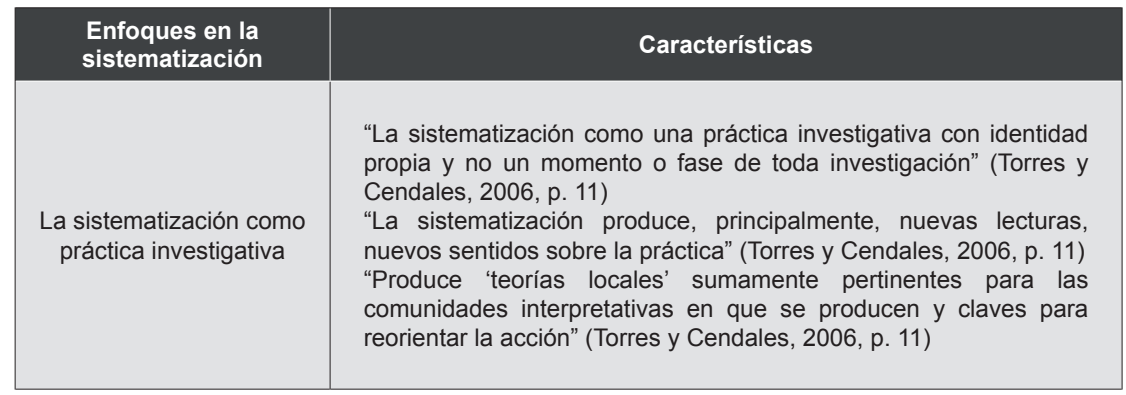

Fuente. Producción propia a partir de Torres y Cendales (2006); Ghiso (1998) y Barnechea (1994).

\section{Referencias bibliográficas}

Barnechea. M., González, E. y Morgan M. (1994). La sistematización como producción de conocimientos. Taller Permanente de Sistematización-CEAAL Lima (Perú). Recurso electrónico hallado en: http://unpan1.un.org/intradoc/groups/public/documents/icap/ unpan033275.pdf Recuperado el día 11 de marzo de 2016-

Bolivar, A. (2002) "¿De nobis ipsis silemus?": Epistemología de la investigación biográficonarrativa en educación. Revista electrónica de investigación Educativa. Universidad de Granada. Facultad de Ciencias de la Educación. España. Recurso electrónico hallado en: http://redie.uabc.mx/redie/article/view/49/1246 Recuperado el día 24 de enero de 2016

Cendales, L. y Torres, A. (2006). La sistematización como experiencia investigativa y formativa 1. Alfonso Torres Carrillo. Recurso electrónico hallado en: http://www. cepalforja.org/sistem/documentos/lola_cendales-alfonso_torres-la_sistematizacion_ como_experiencia_investigativa_y_formativa.pdf Recuperado el día 11 de marzo de 2016

Freire, P. (1997). La importancia de leer y el proceso de liberación. México, Siglo XXI.

Ghiso, A. (1998). De la practica singular al diálogo con lo plural. Aproximaciones a otros tránsitos y sentidos de la sistematización en épocas de globalización. Revista Funlam (Corporación universitaria Luís Amigó). Recurso electrónico hallado en: www.cepalforja. org/sistem/sistem_old/Ghiso.doc Recuperado el día 24 de enero de 2016

Jara, O. (2013). Orientaciones teórico-prácticas para la sistematización de experiencias. Recurso electrónico de Biblioteca Electrónica sobre Sistematización de Experiencias.

Disponible en:http://www.bibliotecavirtual.info/wpcontent/uploads/2013/08/

Orientaciones_teorico-practicas_para_sistematizar_experiencias.pdf Recuperado el día 12 de septiembre de 2015 
Jara, O. (2012) Sistematización de experiencias, investigación y evaluación: aproximaciones desde tres ángulos. Revista Educación Global Research (Agencia Española de Cooperación Internacional para el Desarrollo (AECID)). Num. 1. Recurso electrónico disponible en: http://educacionglobalresearch.net/wp-content/uploads/02A-JaraCastellano.pdf Recuperado el día 12 de septiembre de 2015.

Martinic, S. (1998). El objeto de la sistematización y sus relaciones con la evaluación y la investigación. Medellín, Fundación Universitaria Luis Amigó-CEAAL. Recurso electrónico hallado en: http://www.alboan.org/archivos/337.pdf Recuperado el día 11 de marzo de 2016

Piedrahita, C. (2011) Sistematización de experiencias. Una reflexión desde las rupturas y los márgenes. En: Sistematización de experiencias: innovaciones y subjetivaciones (comp). IDEP - Universidad Distrital Bogotá. 